\title{
A Incompletude do Processo de Disciplinarização das Literaturas Africanas
}

\author{
LUÍS KANDJIMBO \\ Universidade Gregório Semedo \\ Universidade Agostinho Neto
}

\begin{abstract}
In the present essay, I propose a meta-theoretical and interdisciplinary articulation of themes and problems that point to the need for African literary comparativism. In particular, I examine the controversies that have emerged in the theories and criticism devoted to African literatures in light of the debates that likewise took place in African philosophy. The key concept with which I operate is disciplinarization; this is due to its potential for explaining the incomplete nature of the process that might lead to the integration of African Literary Studies or African Literatures in the current disciplinary system.
\end{abstract}

Keywords: African literary criticismo; disciplinarization; epistemology; African literary Studies; African literatures.

Foi há mais de cinquenta anos que a maior parte dos países africanos alcançaram as independências políticas, seguindo-se o lançamento das bases para a construção de Estados modernos. Nesse período o continente foi assolado por crises de diversa ordem cujos efeitos mais devastadores tiveram o seu impacto nos sistemas de ensino superior. Uma das repercussões mais graves dessas crises ocorreu ao nível da produção do conhecimento científico e da legitimação literária onde a hegemonia dos modelos teóricos e metodológicos ocidentais pareciam perpetuar a dependência da actividade científica e literária em África. Tal ideia é bem ilustrada por Inocência Mata, ao referir-se à dependência dos 
escritores de países africanos de língua portuguesa relativamente às instâncias externas de legitimação europeias (Mata 104). Partindo dessa experiência histórica, dos circunstancialismos e contingências que marcaram os Africanos de um modo geral, o meu olhar sobre o continente não dispensa as especificidades e a diversidade do todo.

Quando em 1982, o filósofo congolês V.Y. Mudimbe no seu livro L'Odeur du Père: Essai sur des limites de la science et de la vie en Afrique Noire, numa leitura inspirada pela lição inaugural proferida pelo filósofo francês Michel Foucault no Collège de France, levantava interrogações acerca do estatuto dos discursos africanos e sua ordem, bem como da soberania que os governa e sua orientação. Vivia-se já o apogeu dos processos de legitimação dos discursos e das disciplinas que conformam as Ciências Sociais e Humanas em África. Para Mudimbe estava em causa a necessidade de escapar às malhas do Ocidente. $\mathrm{O}$ que implicava conhecer em profundidade o limite até ao qual o Ocidente se aproximara insidiosamente de África e pressupunha a descoberta naquilo que nos permite pensar contra o Ocidente o que é ainda ocidental (Mudimbe 44).

$\mathrm{Na}$ verdade, a legitimação dos Estudos Africanos e as suas condições de possibilidade enquanto campo do saber constituem expressões que revelam as dinâmicas da modernidade africana, concretizando-se esta através da absorção dos princípios que modelam a ossatura da modernidade ocidental: o princípio da subjectividade, o princípio da tirania da razão e o princípio da redução do mundo à uniformidade. Neste sentido, a modernidade "deve ser despojada da sua carga evolucionista, etnocêntrica e milenar de modo a dar lugar à relativização do seu conceito em função dos valores e das identidades culturais específicas de cada povo, cada civilização" (Kovouama 34). É, pois, no contexto da modernidade africana que os Estudos Africanos e as Literaturas Africanas parecem adquirir o estatuto de campo disciplinar, sendo, por isso, indispensável o estudo da origem das instituições e das disciplinas que constituem os vários campos do saber em África, a reflexão sobre o processo de consolidação do sistema disciplinar moderno e suas influências na constituição de ramos específicos, especialmente o domínio da literatura.

Ao partir da institucionalização da literatura no contexto da modernidade ocidental, uma pergunta se impõe. Será que existem aspectos universais nas

\footnotetext{
${ }^{1}$ Todas as traduções de citações em francês e inglês são da minha inteira responsabilidade.
} 
teorias europeias ou ocidentais susceptíveis de aplicação válida às Literaturas Africanas ou à Literatura Angolana?

A existência de universais que permitem a comunicação intercultural não pode reduzir-se ao reconhecimento do monismo ou do universalismo realista. É que a natureza insidiosa das pretensas teorias universais fora denunciada já em 1964 pelo escritor nigeriano Chinua Achebe, ao considerar que a universalidade é um dogma falso e perigoso embora a atracção que suscita não pareça inspirar qualquer contestação (Achebe 52). Em 1972, a revista Diogène patrocinada pelo Conselho Internacional de Filosofia e de Ciências Humanas e pela UNESCO, consagrou um número à crítica africana sob o título La Littérature Africaine à l'Age de la Critique. Na sua introdução, Roger Caillois, o redactor-chefe, sublinhava que as Literaturas Africanas entravam numa nova fase, a partir do momento em que se transformavam em seu próprio objecto. Tratava-se então de compreender e explicar a criação literária, de lhe captar os motivos secretos, de descrever as suas dèmarches, de explicitar a sua significação (Caillois 3-7).

Tomando os argumentos expendidos pelo filósofo ganense Kwasi Wiredu, numa reflexão sobre os universais e os particulares da cultura, pode-se admitir que as categorias de necessidade e de contingência, aplicadas no âmbito deste debate, permitem compreender que os princípios e os padrões de avaliação estética são contingentes, não havendo, por conseguinte, princípios universais válidos (Wiredu 21-33). As posições de Wiredu abalam a crença na autoridade dos discursos, teorias e epistemologias de origem ocidental.

Com efeito, as condições de possibilidade de uma teoria literária e da crítica literária africana são hoje reconhecidas por alguns sectores da comunidade científica especializada. Em The John Hopkins Guide to Literary Theory \& Criticism publicado em 1994, há uma entrada que lhes é dedicada. No respectivo verbete lê-se o seguinte: "A teoria e crítica literária Africana emerge de um discurso do nacionalismo /continentalismo constituído em acto de resistência política e cultural. ... O desenvolvimento de uma prática e de uma teoria literária global (ou nacional) Africana é inseparável do projecto total de descolonização" (Groden e Kreiswirth 5-8).

Referindo-se ao campo das Literaturas Africanas em que se inscreve a literatura oral, aos universais e particularismos, o crítico literário e ensaísta nigeriano Abiola Irele escreve: 
O ponto que deve ser sublinhado é constituído por situações que distinguem as Literaturas Africanas enquanto campo abrangente, englobando convenções da expressão imaginativa e revelando as diferentes tradições da análise literária. Tais situações representam uma possível posição estratégica que permite operar com uma perspectiva geral sobre o fenómeno literário, mais inclusiva do que a estabelecida pelo cânone ocidental. Visto que o postulado de uma experiência universal e não diferenciada da literatura é indefensável, contudo há-de ser útil, do ponto de vista teórico e metodológico, para examinar as linhas de convergência que aproximam as várias tradições literárias a outras apesar das diferenças de linguagem, convenções e desenvolvimento histórico. (xvi-xvii)

Abiola Irele sintetiza aí os aspectos mais relevantes que têm vindo a merecer a apreciação de outros críticos e teóricos Africanos. Tais aspectos comportam igualmente obras literárias. Mas não deixa de ser relevante apontar os contextos em que parte considerável dos debates teóricos se desenvolveu, ao longo dos últimos cinquenta anos. Estou a referir-me aos colóquios realizados em África: Makerere (1962); Dakar (1963); Freetown (1963); Abidjan (1969, 1970); Yaoundé (1973); Lumbumbashi (1975); Lagos (1977); and Brazzaville (1981).

Entre as obras de referência destaco as seguintes: Actas do Colóquio de Yaoundé. La Critique africain et son Peuple comme producteur de civilisation (1973); Mohamadou Kan, Roman Africain et Tradition (1982); J.P.Makouta Mboukou, Introduction a l'étude du Roman Négro-Africaine de Langue Française (1980); Isidore Okpewho, African Oral Literature. Backgrounds, Character and Continuity (1992); Tejumola Olanyan e Ato Quayson (ed.), African Literature. An Anthology of Criticsm and Theory (2007), Mamoussé Diagne, Critique de la Raison Orale. Les Pratiques Discursives en Afrique Noire (2005). Ao proceder à leitura destas obras, podemos concluir que tem razão Georges Ngal, quando concorda com Chinua Achebe, afirmando que uma teoria das Literaturas Africanas tornar-se-á possível apenas "se evitarmos a armadilha do recurso ao universal" (Ngal 129). Na mesma senda está Pius Ngandu Nkashama, quando defende a possibilidade de uma teoria das Literaturas Africanas ou ainda J.P. Makouta Mboukou.

Analisando as consequências da constituição das Literaturas Africanas como disciplina académica e a disputa sobre a produção do discurso legítimo entre 
investigadores Africanos e não-Africanos, o cerne da questão situa-se na desigual relação de poder existente entre os dois campos do ponto de vista dos recursos, em matéria de investigação (Jeyifo, "The Nature of Things" 33-48). Os países africanos de língua portuguesa e as respectivas literaturas ausentes do campo em que se registavam tais disputas integram as forças que nele interagem já em meados das décadas de 70 e 80, quando a investigação e o ensino das Literaturas Africanas se consolidavam no continente.

Por outro lado, nessa mesma década as comunidades disciplinares dos estudos literários, na Europa e nos Estados Unidos da América, desencadeavam controvérsias no domínio da teoria da literatura, pondo em causa a sua utilidade. Se passarmos em revista os textos publicados nesse período, especialmente aqueles que resultam dos debates gerados pelo texto Against Theory (1985), assinado por Steven Knapp e Walter Benn Michaels, verificamos que o ataque à teoria representava a formulação de dúvidas sobre a pretensa validade universal da teoria da literatura, após a falência dos modelos propostos pelo estruturalismo francês e pelo New Criticism norte-americano. Este modo de levantar o problema era já um sintoma nas obras publicadas por Paul Feyerabend, nomeadamente, em Farewell to Reason (2003) e Against Method (1987), relevando da epistemologia e da filosofia das ciências e que se fundava na necessidade de introduzir as contingências e os acasos na racionalidade científica.

A abordagem que proponho inscreve-se no domínio da metateoria e faz apelo a uma articulação interdisciplinar de temas e problemas que apontem para a necessidade de um comparativismo literário africano. As controvérsias que se registam no domínio da teorização e da crítica das Literaturas Africanas serão analisadas à luz dos debates que desencadeiam igualmente no campo das Filosofias Africanas. O conceito-chave com que opero neste trabalho é o de disciplinarização, devido ao potencial que oferece para explicar a natureza da incompletude do processo que nos irá conduzir à integração dos Estudos Literários Africanos ou das Literaturas Africanas no sistema disciplinar actual. Por disciplinarização entendo o processo de delimitação de uma determinada disciplina, por força de dinâmicas endógenas e exógenas, durante o qual se transita de uma fase pré-disciplinar para a fase disciplinar, admitindo-se nesta última fase a existência, por um lado, de uma compatibilidade entre os fundamentos epistemológicos e metodológicos da produção e transmissão de conhecimentos e, por outro lado, a especificidade do objecto de estudo. A 
profissionalização disciplinar há-de ser uma consequência desse processo e, especialmente, da formação de uma comunidade científica integrada por agentes que, conhecendo profundamente a história e os universos de referência da disciplina, sejam capazes de aplicar as metodologias mais adequadas no domínio da investigação e do ensino.

\section{A Institucionalização dos Estudos Literários Africanos}

Para compreender os fundamentos epistemológicos dos Estudos Africanos nos quais se inscrevem os Estudos Literários Africanos, importa interrogar-nos sobre o momento a partir do qual se constituem como campo disciplinar, dando lugar ao processo de produção do conhecimento sobre o continente africano. Numa abordagem histórica e comparada dos Estudos Africanos, enquanto investigação especializada sobre as sociedades e culturas africanas, a que também se designa por "africanismo," observa-se que eles são uma emanação das políticas coloniais da Alemanha, Grã-Bretanha, França e Bélgica, potências que disputavam a ocupação efectiva de África, procurando conferir à sua presença uma legitimação científica mais intensa, durante as duas primeiras décadas do século XX. Foi na Alemanha onde, em 1910, ocorreu a primeira experiência de institucionalização académica dos Estudos Africanos, por ocasião da nomeação de Diedrich Westermann como professor do Departamento de Línguas Orientais na Universidade de Berlim. Seguiu-se a Grã-Bretanha consagrando esse domínio do saber com a criação do International Institute of African Languages and Cultures, em 1926, que passou a publicar a revista África. O surgimento da School of Oriental and African Studies na Universidade de Londres, em 1939, substituindo a School of Oriental Studies, testemunha a existência de uma comunidade de investigadores, antropólogos e sociólogos, que realizavam já pesquisas em África. Em França, a investigação neste domínio adquire uma dimensão institucional alguns anos mais tarde, após a fundação da Sociétè des Africanistes em 1930.

Ora, é legítimo levantar questões acerca do carácter africano dos Estudos Africanos e da unidade das suas disciplinas, tal como faz Paulin Hountondji. Ao esboçar as suas respostas, partindo do pressuposto de que a actividade científica em África pode ser qualificada como "extravertida" e "destinada a ir ao encontro das necessidades teóricas dos nossos parceiros ocidentais e responder às 
perguntas por eles colocadas" (Hountondji 157), Hountondji escreve: "Os chamados estudos africanos ... se baseiam em metodologias e teorias que se consolidaram em vários campos . . . muitos antes de terem sido aplicadas a África enquanto novo campo de estudo (150-51). Portanto, é perfeitamente admissível discernir perspectivas radicalmente diferentes defendidas por Africanos e nãoAfricanos, no que diz respeito à semântica dos Estudos Literários Africanos e suas disciplinas.

$\mathrm{Na}$ organização institucional das universidades, os Estudos Literários Africanos constituem-se após a Segunda Guerra Mundial. Foi nas décadas de 40 e 50 que surgiram as primeiras universidades africanas do século XX. Mas a formação dos Estados independentes ocorre a partir da década de 60, obedecendo ao modelo ocidental e herdando as fronteiras e as instituições políticas das antigas potências coloniais. A edificação de sistemas de ensino que pudessem incorporar conteúdos programáticos sem qualquer influência externa foi imediata. Em alguns países africanos as mudanças curriculares de matérias respeitantes às Literaturas Africanas ocorreram logo a seguir à independência. É o que sucedeu com o Senegal, onde se realizou o primeiro colóquio consagrado ao ensino das Literaturas Africanas, em 1962. Na Universidade de Dakar assim como na maior parte das universidades africanas, a esta disciplina fora conferido um estatuto semelhante a outras disciplinas leccionadas, no âmbito da organização de departamentos autónomos (Kane, "L’Ensegnement” 27-39). Quanto ao ensino secundário, as Literaturas Africanas, sustenta Kane, foi introduzida de modo anárquico, sem métodos, sem programas. Numa perspectiva comparada, verifica-se que nos países africanos de língua francesa, o ensino das Literaturas Africanas nas universidades e nas escolas secundárias se consolida em princípios da década de 70. Por exemplo, a introdução de textos literários africanos (incluindo a literatura oral tradicional) ocorre apenas em 1972, após a Conferência de Ministros da Educação, realizada em Madagáscar.

Nos países africanos de língua inglesa, o mais expressivo sinal de mudança produz-se por um texto datado de 1968, subscrito por três autores originários da África Oriental, através do qual defendem a abolição do Departamento de Inglês na Universidade de Nairobi e a criação do Departamento de Línguas e Literaturas Africanas (Wa Thiong'o 145-50). Tal como diz Biodun Jeyifo, "the constitution of African literary study as a legitimate academic discipline with 
certified degrees and professional specialization began in Africa, not in Europe or America" (Jeyifo, "The Nature of Things" 43-45). Pode dizer-se que o centro inaugural de gravidade de um ensino sério das Literaturas Africanas está situado em África.

Ao apresentar as conclusões do um inquérito sobre o ensino das Literaturas Africanas nas universidades dos países africanos de língua inglesa, Bernth Lindfors, observa que a descolonização dos estudos literários em África estava em curso e em estado bastante avançado. Nota que dos 194 cursos seleccionados em 30 universidades do universo de 14 países, a amostra representava cerca de $60 \%$ do número total de cursos em que se inscrevem 226 autores. A conclusão a que chega o referido investigador permite sustentar a ideia de que as Literaturas Africanas ocupavam um lugar significativo nos programas dos Departamentos de Inglês, Departamentos de Literaturas Africanas ou Departamentos de Línguas Europeias (Lindfors, Long Drums and Canons 45-59). Estes indicadores estatísticos fornecem um quadro que reflecte, provavelmente, de igual modo a situação dos países de língua francesa. Efectivamente, a investigação e o ensino das Literaturas Africanas tinham alcançado níveis sem precedentes, especialmente no que diz respeito à sua institucionalização académica. Ignora-se, no entanto, e com alguma razão o que se passa nos países africanos de língua portuguesa.

\section{A Denominação de uma Disciplina: Literaturas Africanas ou Literatura Africana?}

O processo de autonomização disciplinar das Literaturas Africanas foi dando origem ao abandono das denominações generalistas elaboradas na base de critérios raciais. A historiografia regista influências profundas que o movimento panafricanista e posteriormente a Negritude exerceram sobre as ideologias dos escritores Africanos. Durante muito tempo as Literaturas Africanas eram adjectivadas com fundamento no critério falacioso da raça. Era comum o uso de expressões como "literatura negro-africana," "literatura neo-africana" ou simplesmente "literatura negra." Para justificar tais designações, Lilyan Kesteloot, na sua Anthologie Négro-Africaine, argumenta: 
Consideramos a literatura negro-africana como manifestação e parte integrante da civilização africana. E mesmo quando é produzida num meio culturalmente diferente, anglo-saxónico nos Estados Unidos, Ibérico em Cuba e no Brasil. . . . O espaço da literatura negro-africana cobre não apenas a África ao sul do Sahara, mas todos os cantos do mundo onde se estabeleceram comunidades Negras, sob os auspícios de uma história turbulenta que arrancou ao Continente centenas de milhões de homens como escravos.... . (5-6)

O tipo de argumentos aduzidos por autores como Kesteloot (literatura negroafricana), Janheinz Jahn (literatura neo-africana) ou Jacques Chevrier (literatura negra) não oferecem qualquer consistência teórica para merecerem a dignidade que lhes é conferida. A partir da década de 70 e 80, a tendência dominante da crítica designa as Literaturas Africanas no plural, confinando-as aos espaços nacionais. Passam a ser publicados estudos e antologias que obedecem ao critério da nacionalidade literária. Deste modo, Literaturas Africanas ou Literatura Africana é a denominação de uma disciplina que pela sua vocação generalista contradiz a lógica do Estado-nação de que emana do paradigma filológico nacional em que se funda o ensino das Literaturas Europeias. Não é raro encontrar professores e investigadores europeus e americanos que, negando a existência de literaturas nacionais em África, defendem a denominação colectiva destas literaturas enquanto disciplina cuja definição depende do seu vínculo com as línguas europeias em que são escritas, sendo, por isso, leccionadas no âmbito de Departamentos de Estudos Ingleses, Franceses ou Portugueses. Por ausência de uma robusta epistemologia africana independente, observam-se repercussões deletérias dessa hierarquização nas universidades africanas. Deste modo, a investigação e o ensino das várias Literaturas Nacionais do continente africano em muitos casos ainda assentavam em duas hipóteses erradas. Em primeiro lugar, a denominação generalista de Literatura Africana ou Literaturas Africanas que elimina a possibilidade de passar à compreensão das suas especificidades. Em segundo lugar, a balcanização linguística dos estados que está na origem da marginalização das Literaturas Africanas de Língua Portuguesa dos Estudos Literários Africanos cuja denominação disciplinar (Literaturas Africanas de Expressão Portuguesa) em países como Portugal revela a pervivência de um paternalismo colonial que se manifesta através de uma: 
. . mal disfarçada resistência contra o reconhecimento do significado próprio das chamadas Literaturas Africanas de Expressão Portuguesa; fruto, em parte, de reminiscências ideológicas de raiz colonialista, essa resistência funda-se também na leitura de tais literaturas à luz do cânone literário português e europeu, leitura que, desse ponto de vista, é naturalmente desqualificadora. (Reis 77)

Apesar disso, o volume de trabalhos de investigação consagrados às Literaturas Africanas de Língua Portuguesa deu lugar à sua disciplinarização em várias universidades do mundo. Se entendermos que o processo de disciplinarização comporta duas fases, uma pré-disciplinar e outra disciplinar, concluiremos que à primeira chega-se em finais da década de 70. Mas a fase disciplinar não alcançou a sua consolidação.

$\mathrm{Na}$ fase disciplinar destacamos nomes de três professores universitários, os discipline-builders, nomeadamente Gerald Moser e Russell Hamilton dos Estados Unidos da América, Manuel Ferreira de Portugal e Maria Aparecida Santilli do Brasil.

Manuel Ferreira notabiliza-se como o responsável pela introdução da disciplina de Literaturas Africanas de Expressão Portuguesa na Faculdade de Letras da Universidade de Lisboa, em 1974. Seguiram-se as Faculdades de Letras da Universidade do Porto em 1975, pela mão de Salvato Trigo e, em 1980, as Faculdades de Letras da Universidade de Coimbra e da Universidade Nova de Lisboa. A sua institucionalização ocorreria em 1978, através do Decreto-Lei $\mathrm{n}^{\mathrm{o}}$ 53/78 de 31 de Maio e do Decreto-Lei ${ }^{\circ}$ 75/84 de 27 de Novembro. Os primeiros Mestrados e Doutoramentos foram criados nos anos 80 do século XX pelas universidades em que se leccionava a disciplina ao nível da licenciatura.

No Brasil, em 1984 discutia-se ainda a legitimação do ensino das Literaturas Africanas nos cursos de Letras. Durante as duas décadas que se seguiram, ao que parece a situação não sofreu alterações significativas, apesar da "última proposta de reformulação curricular," tal como nos diz a professora Laura Padilha (2010: 4) que chega mesmo a defender, em matéria de ensino das Literaturas Africanas de Língua Portuguesa, a necessidade de uma "descolonização curricular" para o Brasil. 
Chamo a atenção para o facto de incidirmos a reflexão sobre as Literaturas Africanas de Língua Portuguesa em geral. Não rigorosamente das literaturas nacionais de cada um destes países. É de ensino das Literaturas Africanas de Língua Portuguesa que se trata. Levanta-se aqui a possibilidade de estarmos perante duas disciplinas, Literaturas Africanas de Língua Portuguesa e a Literatura de cada um dos países, isto é, Literatura Angolana, Literatura Moçambicana, Literatura Cabo-Verdiana, Literatura da Guiné-Bissau e Literatura de S.Tomé. Relativamente à primeira podemos falar da necessidade de desenvolver um ensino interdisciplinar cruzando os Estudos Africanos e as Literaturas Africanas de Língua Portuguesa, estabelecendo as devidas linhas de diálogo com as Literaturas Africanas de Língua Inglesa e Língua Francesa. No dizer de Jean-Marie Grassin, a aludida perspectiva comparatista começaria por privilegiar a abordagem inter-africana :

Trata-se de valorizar a sua especificidade e o seu papel nos grandes conjuntos literários para os quais ela terá contribuído. . . . Um comparativismo intraafricano permitiria situar, através do estudo dos correlatos externos, a cultura africana no quadro das grandes correntes artísticas, políticas e sociais do planeta. O que é indubitavelmente melhor do que um olhar sobre a palavra africana no seio dos grandes conjuntos exófonos. (257-71)

Portanto, torna-se um imperativo fundamental dos Estudos Literários Africanos proceder à revisão das denominações disciplinares das Literaturas Africanas no plural e das Literaturas nacionais dos países africanos no singular. É que a história da formação das disciplinas demonstra o papel que o nome de uma disciplina e a sua estabilidade desempenham na sua consolidação, além de outros factores como a existência de publicações científicas, nomenclatura profissional, publicidade institucional, comunidades científicas organizadas em associações. Ao nível institucional, a criação de unidades de investigação e ensino nas universidades, tais como Departamento de Línguas e Literaturas Africanas, Departamento de Estudos Literários Africanos, Departamento de Literaturas da África Austral, Departamento de Estudos Comparados Africanos, cursos de pósgraduação, mestrado e doutoramento visando a especialização em áreas como Literatura Angolana, Literatura Moçambicana, Literatura Cabo-verdiana, 
Literatura Oral Tradicional Angolana ou Moçambicana, etc., pode assumir uma importância decisiva.

\section{As Literaturas Africanas Perante a Problemática da Teorização e da Crítica}

A hegemonia das metodologias ocidentais em África cedo começou a ser objecto de dúvida epistemológica muito antes do dealbar das independências políticas africanas, através dos debates sobre a teorização e a crítica das Literaturas Africanas que remontam aos fins dos anos 40, com a teoria da Negritude e a criação da revista Présence Africaine, publicada em Paris, sob a direcção do senegalês Alioune Diop. Nas duas décadas seguintes surgiram revistas especializadas que veiculavam resultados de pesquisa e sustentavam a actividade das instituições do ensino superior. $\mathrm{Na}$ história da crítica literária africana, destacam-se: Afrique Nouvelle; Liaison; Trait d'Union; Bingo; Black Orpheus (1957-82); Abbia; Transition (1961); African Literature Today; Drum; The Horn (Ibadan, 1958-64); Penpoint (Makerere, 1958-70); Okike (An African Journal of New Writing, Nsukka). Igual destaque deve ser dado aos congressos de escritores negros realizados em Paris e em Roma, respectivamente em 1956 e 1959, que contribuíram de certo modo a liquidar o paternalismo ocidental na sua relação com a África.

As décadas de 60 e 70 são marcadas por importantes factos políticos e culturais. As antigas colónias britânicas, francesas e belgas alcançam a independência e dá-se a institucionalização e generalização dos estudos universitários. As Literaturas Africanas são introduzidas nas grelhas curriculares das universidades africanas, designadamente na Faculdade de Letras da Universidade Lovanium de Kinshasa; Faculdade de Letras e Ciências Humanas da Universidade de Dakar; Universidade de Yaoundé; Universidade de Nsukka e Universidade de Ibadan na Nigéria; Universidade do Ghana, que cria o primeiro Instituto de Estudos Africanos; Universidade de Makerere, no Uganda. A universidade do Congo Democrático, antigo Zaire, será a primeira a introduzir o ensino e a investigação das literaturas africanas (Mateso 1986:139). Mas é no espaço anglófono onde encontraremos as figuras mais proeminentes na produção de um discurso crítico que pretende romper com os modelos ocidentais.

Na África Oriental, como vimos, desenvolve-se uma corrente pragmática liderada pelo escritor e professor universitário queniano, Ngũgĩ wa Thiong’o que, 
com Henry Owuor-Anyumba e Taban Lo Liyong (ugandês), lança o projecto de abolição do Departamento de Inglês na Universidade. Defendem a constituição do Departamento de Literaturas e Línguas Africanas. Os fundamentos de tal tese assentam na necessidade urgente de afastar o espectro de uma África vista como simples extensão do Ocidente, procurando instituir uma visão africana dos estudos literários.

Seguem-se várias manifestações de ruptura do ponto de vista historiográfico, teórico e crítico. Em 1970, Thomas Melone, num seminal artigo lançava o repto. No seu entender, "por se pretender técnica e criativa, a tarefa do crítico situa-se a um outro nível. Tal é imposto ou sugerido pela problemática da linguagem, quer dizer da estrutura profunda da obra" (Melone 3-19). Em termos metodológicos considera que "o objectivo ... é apresentar ao público mundial as obras mais significativas da nossa literatura assente na nossa própria sensibilidade estética, da nossa própria avaliação das civilizações negroafricanas, da nossa própria visão do devir africano" (6).

Quando se aborda hoje o discurso crítico sobre as Literaturas Africanas, o problema releva da demarcação dos seus limites e finalidades perante o fascínio que as metodologias ocidentais suscitam. No que diz respeito à crítica literária e aos discursos africanos em geral, há que determinar os fundamentos e os postulados teóricos que satisfaçam imperativos do momento. Sem tais aspectos preliminares, "a crítica não pode operar senão como um mimetismo da palavra, sem influência real, quer sobre o texto quer sobre o contexto que lhe subjaz" (Nkashama 241).

Se a crítica literária africana integra os sistemas literários nacionais, ela pressupõe uma teorização que deve ser autónoma, co-envolvendo problemáticas de ordem epistemológica. Tal reflexão permite trazer à liça questões acerca do sujeito e do objecto do discurso, dos métodos, princípios operatórios e das condições da sua eficácia. Não pode a instauração da crítica literária surgir do nada. Ao invés, admite Locha Mateso, parte do pressuposto de uma precedência dos fundamentos da crítica relativamente ao surgimento das literaturas escritas. Ainda de acordo com Locha Mateso, "a crítica literária na África tradicional é uma actividade de múltiplas facetas . . . concentra os critérios de apreciação que correspondem à finalidade conferida à obra por um determinado grupo social" (Mateso 55). 
O objecto da crítica literária africana é constituído por um conjunto de textos resultantes de dois sistemas de comunicação: a comunicação oral e a comunicação escrita. Do primeiro temos a literatura oral e do segundo temos a literatura escrita. Perante este quadro heterogéneo de textos, a posição e a atitude dos sujeitos dos discursos críticos têm-se revelado polémicas. A variedade de textos assim como os problemas que se colocam na sua recepção têm suscitado suspeitas quanto a relativa ineficácia da utensilagem teórica e crítica ocidental, opondo críticos Africanos a não-Africanos. Afirma-se assim, progressivamente, aquilo a que Nouréini Tidjani-Serpos chama "tendência especifitária" que se caracteriza pelo facto de privilegiar as diferenças intrínsecas que conferem originalidade às obras literárias (Tidjani-Serpos 123).

Eldred Jones observa que "as literaturas africanas apresentam uma importância capital para os Africanos e deve-se, naturalmente sobre esta matéria esperar dos críticos africanos opiniões substantivas" (Jones: v). Estas considerações impõem-se com algum vigor ao serem transpostas para o plano institucional do ensino das Literaturas Africanas. Pode dizer-se que a manifestação dos debates entre críticos Africanos e não - Africanos e as modalidades dessa conflitualidade não parece ser apenas uma "deslocada hostilidade," como diz Solomon Ogbede Iyasere (Iyasere 21).

Por outro lado, os próprios críticos não-Africanos revelam-se insatisfeitos com os instrumentos que utilizam. Edgar Wright refere que o crítico ocidental que se dedica ao estudo das modernas Literaturas Africanas enfrenta duas grandes obstruções: a primeira reside em saber se qualquer teoria geral pode funcionar, quando aplicada a uma cultura que é completamente diferente nas suas origens daquela que constitui o suporte material da teoria . . . ; a segunda relaciona-se com o público leitor e a intencionalidade do autor" (Wright 8).

Num artigo publicado em 1969, na revista Présence Africaine, o nigeriano Joseph Okpaku demarcava o alcance e os limites da intervenção das duas críticas. Observa que "o primado da crítica das artes africanas deve ser conferido aos Africanos fazendo uso de padrões africanos" (Okpaku 137-146). Por outro lado, continua Okpaku, o papel do crítico ocidental é diferente na medida em que "a única actividade válida deste último consiste em interpretar as Literaturas Africanas e outras artes para audiências ocidentais" (Okpaku 141). Com efeito, as posições que fazem a apologia dessa primazia são bem mais antigas. Remontam aos anos dos congressos de escritores negros. A este respeito, a 
investigadora belga Lylian Kesteloot, escrevia: "Estou convencida de que só os críticos Africanos serão capazes de destilar toda a essência, sabor, significado e poesia, toda a 'suculência dos frutos' de sua herança ancestral para maior glória da literatura mundial" (Kesteloot, Histoire 5-6).

Encontramos algumas das mais significativas manifestações da conflitualidade entre críticos Africanos, negadores e defensores do monopólio do discurso crítico legítimo na revista African Literature Today, especialmente no seu número dedicado à crítica (Focus on Criticism). No editorial dessa edição Eldred Jones, que foi editor da revista, advogava já a tese do primado da crítica endógena. Na mesma senda inscreve-se Thomas Melone, quando escrevia no artigo publicado em 1970: "A situação actual nos impõe uma revisão total do processo. Trata-se de restituir ao povo o privilégio de que foi detentor durante os tempos imemoriais. . . . O problema essencial consiste em não perder de vista o que na tradição constituía a base da crítica artística e literária tal como o povo a exercitava" (Melone 3-19).

Solomon Ogbede Iyasere, no texto inserido na referida revista, sustenta que "não é por sermos Africanos que as nossas explicações serão melhores que as do crítico não-Africano" (Iyasere 20-27). Ele reage ao requisitório produzido por Ernest Emenyonu contra o crítico americano Bernth Lindfors. Este ataque suscitou outros comentários por parte de Solomon O. Iyasere. Condena Emenyonu por agir "como se fosse um cego perante a virtude que permite distinguir as situações e factos, pois ele fecha os olhos à diferença entre a arte e a realidade, representação artística e reprodução fotográfica" (Iyasere 20-27).

A controvérsia entre o nigeriano Ernest Emenyonu e norte-americano Bernth Lindfors prova não apenas o fervor do debate, mas sobretudo o patente "buraco de inteligibilidade" que justifica a emergência de argumentos que se reconduzem ao relativismo epistémico. Emenyonu ataca a mediocridade do discurso crítico dos não-Africanos, nos seguintes termos: "O que muitos críticos ocidentais enunciam sobre as Literaturas Africanas são reflexões que revelam uma profunda falta de conhecimento sobre as tradições culturais Africanas associadas à ignorância da existência, natureza e profundidade das Literaturas Orais Africanas" (Emenyonu 10).

Mais adiante, Emenyonu introduz uma reserva relativamente às eventuais interpretações das suas palavras, afastando qualquer vontade de monopólio: 
Com tudo isso não se pretende dizer que os críticos Africanos se jactam como os juízes mais qualificados em causa própria, na avaliação das obras de autores Africanos. Talvez estejam em melhores condições de oferecer juízos sobre obras Africanas, a fim de ajudar o leitor a ganhar a perspectiva dos autores e das realidades em que se inscreve a obra (10).

Lindfors reconhece a existência do problema com que se debatem os críticos nãoAfricanos perante uma obra de arte africana. Em semelhante situação torna-se impossível apresentar uma visão de conjunto. Mas adverte: "De facto, se a interpretação fosse o monopólio dos críticos nativos, a verdade seria encontrada principalmente a nível local, as suas dimensões universais seriam esquecidas" (Lindfors, Long Drums and Canons 53-54).

Entre os negadores da primazia da crítica endógena encontram-se aqueles que sem o declararem explicitamente confirmam o chamado "mimetismo da palavra." Exercem a crítica em dois níveis: "recuperando as variáveis de postulados teóricos ocidentais (únicos susceptíveis de ser considerados como tais e de funcionar como metodologia coerente); e num outro nível o discurso da crítica literária parece limitado, não marcado por quaisquer limites metodológicos" (Nkashama, Ecritures 239).

Apesar dessa oposição que assenta na consideração do primado dos critérios de apreciação, várias têm sido as tentativas para a formulação de respostas. Grande parte destes esforços é empreendida no contexto académico, ensaiandose actualmente, um pouco por todo o continente, novas vias para os estudos das Literaturas Africanas, impondo-se, no entanto, a necessidade da demonstração do seu pleno estatuto disciplinar, na medida em que no plano sociológico e epistemológico tem vindo a ser marcada por uma profunda incompletude e alienação. Todavia, numa observação fundada em dados empíricos, as literaturas nacionais dos países africanos dão-nos uma ilusão disciplinar quando parecem reunir as condições que permitem atribuir-lhes o estatuto de disciplinas.

\section{A Incompletude Disciplinar das Literaturas Africanas}

A incompletude da disciplinarização das Literaturas Africanas manifesta-se através da incompatibilidade existente entre os fundamentos epistemológicos e metodológicos que sustentam a sua teorização, crítica e ensino, por um lado, e a 
especificidade do seu objecto de estudo, por outro. Embora as Literaturas Africanas constituam um campo que atrai a intervenção de especialistas como resultado da divisão do trabalho intelectual, no plano institucional e epistémico não é ainda uma disciplina no sentido pleno, na medida em que é reconhecível um défice de disciplinaridade. Para que tal situação deficitária seja alterada será necessário alcançar o "nosso objectivo final" que, de acordo com Hountondji, consiste no seguinte:

. . . um processo autónomo e autoconfiante de produção de conhecimento e de capitalização que nos permita responder às nossas próprias questões e ir ao encontro das necessidades tanto intelectuais como materiais das sociedades africanas. O primeiro passo nesse sentido seria talvez formular "problemáticas" originais, conjuntos originais de problemas estribados numa sólida apropriação do legado intelectual internacional e profundamente enraizados na experiência Africana.

À luz da sociologia da ciência, a constituição das disciplinas pressupõe a existência de um tipo de organização. Entre os seus indicadores temos: aparato de conceitos e categorias que configuram uma linguagem e normas técnicas; a integração no currículo do ensino superior; métodos e programas específicos; instituições de carácter associativo; profissionalização e consensos da comunidade científica disciplinar; publicações de referência e respectivos índices bibliométricos.

Ora, se concentramos a nossa atenção sobre os países africanos de língua portuguesa, percebe-se que o estatuto disciplinar das Literaturas Africanas de Língua Portuguesa há-de ser aparentemente consistente, se o submetermos ao teste de contextualização epistemológica, partindo do postulado segundo o qual o conhecimento científico é uma construção social que denuncia as marcas dos sujeitos ou grupo de sujeitos que o produzem bem como as injunções do tempo e do lugar em que se realiza a sua produção.

A noção de campo científico proposta por Pierre Bordieu tem aqui uma relevância particular, na medida em que introduz o elemento de conflitualidade entre os agentes que o integram, pondo em causa a ideia de homogeneidade que parece caracterizar a comunidade científica ou o segmento dos que se dedicam 
aos Estudos Literários Africanos. Os agentes que intervêm no campo científico podem ser sujeitos individuais ou disciplinas. Mas as disciplinas organizam-se numa estrutura hierárquica, de tal modo que elas são definidas pelas propriedades intrínsecas e pela posição que ocupam no espaço das disciplinas (Bordieu 94). Por isso, a luta aparentemente inexistente que os investigadores e especialistas Africanos e não-Africanos travam entre si visa a aquisição de um bem escasso: o monopólio do discurso científico sobre as Literaturas Africanas que vem legitimando a existência de uma profissionalização, podendo dizer-se que o exercício da docência, a leitura e a sua interpretação ocupam um modesto lugar no sistema de disciplinas e sub-disciplinas, garantindo o exercício de uma actividade profissional com a qual se auferem rendimentos para uma vida inteira relativamente confortável como acontece nos Estados Unidos da América (Lindfors, Long Drums and Canons 158). Essas vantagens obtêm-se, em grande parte dos casos, à custa de uma flagrante incompetência de que derivam sentimentos de hostilidade movidos por professores não-Africanos contra os seus colegas Africanos (Nkasama, Ecritures 263).

Se entendermos que a inventariação das controvérsias que ocorrem no campo da teoria da literatura e da crítica literária opondo Africanos e não-Africanos, sugere a ideia de incomensurabilidade e, por conseguinte, a adopção de um relativismo rígido, torna-se necessário compreender, em primeiro lugar, o funcionamento das comunidades científicas, as relações, os consensos e os dissensos que se estabelecem no seu seio. Para tal a atenção deve deslocar-se para os princípios em que assentam as lutas pela imposição e hegemonia no campo científico.

A lógica desta e de outras lutas que ocorrem no campo dos Estudos Literários Africanos não pode ser suficientemente compreendida fora de uma comunidade e correspondente contextualização. Semelhante perspectiva pode suscitar a acusação banalizadora de relativismo, quando se coloca a questão de saber quem são os que têm legitimidade entre agentes, posições e disciplinas que lutam pela hegemonia.

A busca do consenso que mobiliza as comunidades disciplinares dos Estudos Literários Africanos não é rigorosamente o grande objectivo dos agentes que as constituem. Tal se deve à existência da já referida desigual distribuição de recursos no acesso aos espaços de legitimação e confrontação dos agentes. Compreende-se assim que o potencial de dissenso seja mais forte do que o de 
consenso, no contexto de uma assimetria epistémica de tipo vertical que se verifica na relação que os investigadores Africanos estabelecem com os seus pares estrangeiros.

$\mathrm{O}$ consenso epistemológico atravessado pelas práticas da generosidade e pelos factores de legitimação são instrumentos do exercício da hegemonia. É que se o consenso pode ser entendido como produto de "um diálogo submetidos às regras da dialéctica" (Bourdieu 103), tais regras têm uma validade condicionada pelo triunfo da força do melhor argumento apoiado por um reforço institucional. Deste modo afigura-se inevitável avaliar as condições necessárias e suficientes do consenso.

O reconhecimento das assimetrias existentes no campo dos Estudos Africanos suscita a revisão das suas regras e convenções enquanto campo científico. Faz todo sentido questionar a validade universal dos conceitos, hipóteses e instrumentos analíticos originários dos países hegemónicos, com que se opera no campo dos Estudos Literários, sendo indefensável a reivindicação da objectividade e da verdade garantidas como pretendem os "realistas," pois estes pensam que o essencial consiste em afastar-se de qualquer comunidade particular, devendo ser observada a partir de um ponto de vista universal (Rorty 49). Por essa razão, as epistemologias ocidentais suscitam dúvidas sobre a sua eficácia, admitindo sempre a probabilidade de perspectivas concorrentes (Feyerabend, Adieu a la raison 89). Para lá do espaço territorial do Ocidente, deve ser reconhecida a existência de outros mundos e outras tradições, não podendo, por isso, os especialistas não-Africanos reivindicar o monopólio ou a universalidade do saber e da ciência assente exclusivamente na sua experiência. Em comunidades epistémicas que se dedicam aos estudos das Literaturas Africanas será, por conseguinte, legítimo fazer a advocacia do pluralismo teórico e crítico constituindo o relativismo epistémico um princípio fundamental. Temos de repensar o processo de disciplinarização dos saberes e conhecimentos produzidos sobre África e suas Literaturas no século XXI.

\section{Obras Citadas}

Achebe, Chinua. Morning Yet on Creation Day. Londres: Heinemann, 1975. Impresso. 
Adebayo, Grace Aduke. "A crítica do romance da África Ocidental de língua francesa e inglesa: evolução e estado actual." África-Literatura, Arte e Cultura 3.3 (1981): 10-18. Impresso.

Amuta, Chidi. The Theory of African Literature: Implications for Practical Criticism. Londres: Zed, 1989. Impresso.

Piriou, Anne, e Emmanuelle Sibeud, eds. L'Africanisme en Questions. Paris: Centres d'Études Africaines, École dea Hautes Études en Sciences Sociales, 1997. Impresso.

Bates, Robert H., et al., eds. Africa and the Disciplines: The Contribution of Research in Africa to the Social Sciences and Humanities. Chicago: U of Chicago P, 1993. Impresso.

Blanckaert, Claude. "La discipline en perspective: Le système des sciences à l'heure du spécialisme (XIX-XX siècle).” Qu'est-ce qu'une discipline? Ed. Jean Boutier, Jean-Claude Passeron e Jacques Revel. Paris: École des Hautes Études en Sciences Sociales, 2006. 117-48. Impresso.

Bourdieu, Pierre. Para uma sociologia da ciência. Trad. Pedro Eloi Duarte. Lisboa: Edições 70, 2001. Impresso.

Caillois, Roger. "Introduction.” Diogène 80 (1972): 3-7. Impresso.

Chinweizu, Jemie, et al., eds. Toward the Decolonization of African Literature: African Fiction and Poetry and their Critics. Enugu: Fourth Dimension, 1980. Impresso.

Emenyonu, Ernest. "African Literatures: What Does It Take to be its Critic?" African Literature Today 5 (1971): 1-11. Impresso.

Fabiani, Jean-Louis. "À quoi sert la notion de discipline.” Qu'est-ce qu'une discipline? Ed. Jean Boutier, et al. Paris: École des Hautes Études en Sciences Sociales, 2006. 11-34. Impresso.

Feyerabend, Paul. Adieu a la raison. Paris: Seuil, 1989. Impresso.

—. Contra o método. Trad. César Augusto Mortari. São Paulo: UNESP, 2003. Impresso.

Foucault, Michel. A Ordem do discurso. Lisboa: Relógio d’Água, 1997. Impresso.

-.É preciso defender as sociedades. Lisboa: Livros do Brasil, 2006. Impresso.

Gil, Fernando. "Disciplinas." Enciclopédia Einaudi. Lisboa: Imprensa Nacional/Casa da Moeda, 2000. 329-48. Impresso. 
Kandjimbo

Grassin, Jean-Marie. "Dire la parole Africaine aujourd'hui: perspectives pour le renouvellement de l'enseignement et de la recherche en littérature africaine." Littératures africaines et enseignement: Actes du colloque de Bordeaux (Centre d'Éudes Littéraires Maghrebines, Africaines et Antillaises e CNRS). Ed. Mohamadou Kane. Bordéus: PU de Bordeaux, 1985. 257-71. Impresso.

Groden, Michael, e Martin Kreiswirth, eds. The John Hopkins Guide to Literary Theory \& Criticism. Baltimore, MD: The Johns Hopkins UP, 1994. Impresso.

Guillroy, John. "Literary Study and the Modern System of the Disciplines." Disciplinarity at fin de sècle. Princeton, NJ: Princeton UP, 2002. 19-43. Impresso.

Hamilton, Russell G. Voices from an Empire: A History of Afro-Portuguese Literature. Minneapolis: U of Minnesota P, 1975. Impresso.

Hountondji, Paulin. "Conhecimento de África, conhecimento de Africanos: Duas perspectivas sobre os Estudos Africanos." Revista Crítica de Ciências Sociais 80 (2008): 149-60. Impresso.

Irele, Abiola, The African Imagination: Literature in Africa and Black Diaspora. Oxford: Oxford UP, 2001. xvi-xvii. Impresso.

Iyasere, Solomon Ogbede. "African Critics on African Literature: A Study in Misplaced Hostility." African Literature Today 7 (1982): 20-27. Impresso.

Jewsiewicki, Bogumil. "African Studies: France and the United States." The Study of Africa: Global and Transnational Engagements. Ed. Paul T. Zeleza. Dakar, CODESRIA, 2007. 127-45. Impresso.

Jeyifo, Biodun. "The Nature of Things: Arrested Decolonization and Critical Theory." Research in African Literatures 21.1 (Spring 1990): 33-48. Impresso.

-. "The Debate on Literary Pedagogy in Africa: The Ife Experience." Littératures africaines et enseignement: Actes du colloque de Bordeaux (Centre d'Éudes Littéraires Maghrebines, Africaines et Antillaises e CNRS). Ed. Mohamadou Kane. Bordéus: PU de Bordeaux, 1985. Impresso.

Jones, Eldred, ed. African Literature Today 7 (1982). Impresso.

Kane, Mohamadou. Roman Africain et Tradition. Dakar, Nouvelles Editions Africaines, 1982. Impresso. 
-, ed. Littératures africaines et enseignement: Actes du colloque de Bordeaux (Centre d'Éudes Littéraires Maghrebines, Africaines et Antillaises e CNRS). Bordéus: PU de Bordeaux, 1985. Impresso.

Kelly, Donald R. "Le problème du savoir et le concept de discipline." Qu'est-ce qu'une discipline? Ed. Jean Boutier, et al. Paris: École des Hautes Études en Sciences Sociales, 2006. 97-115. Impresso.

Kesteloot, Lilyan. Histoire de la Littérature Négro-Africaine. Paris: Karthala, 2004. Impresso.

-. Anthologie Negro-Africaine (Littérature de 1918 à 1981). Verviers: Les Nouvelles Editions Marabout, 1978. 5-6. Impresso.

Kouvouama, Abel, La Modernité en question. Paris: Paari, 1996. Impresso.

Lindfors, Bernth. Long Drums and Canons: Teaching and Researching African Literatures. Lawrenceville, NJ: Africa World P, 1995. 45-59. Impresso.

—. "The Blind Men and the Elephant." African Literature Today 5 (1982): 5364. Impresso.

Lopes, Silvina Rodrigues. A Legitimação em Literatura. Lisboa: Cosmos, 1994. Impresso.

Margarido, Alfredo. Estudos sobre literaturas das nações africanas de língua portuguesa. Lisboa: A Regra do Jogo, 1980. Impresso.

Mata, Inocência. A Literatura Africana e a crítica pós-colonial: Reconversões. Luanda: Nzila, 2007. Impresso.

Mateso, Locha. La littérature Africaine et sa Critique. Paris: ACCT-Karthala, 1986. Impresso.

Mboukou, J.P. Makouta. Introduction à l'étude du Roman Négro-Africaine de Langue Française. Dakar: Nouvelles Editions Africaines, 1980. Impresso.

Melone, Thomas. "La critique littéraire et les problèmes du langage: point de vue d'un Africain." Présence Africaine 73 (1970): 3-19. Impresso.

Mitchell, W.J.T., ed. Against Theory: Literary Studies and the New Paradigm. Chicago: U of Chicago P, 1985. Impresso.

Mudimbe, V.Y. L'Odeur du Père: Essai sur des limites de la science et de la vie en Afrique Noire. Paris: Présence Africaine, 1982. Impresso.

Ngal, Georges. Création et Rupture en Littérature Africaine. Paris: L'Harmattan, 1994. Impresso.

Nkashama, Pius Ngandu. Ecritures et Discours Littéraires. Paris: L'Harmattan, 1989. Impresso. 
—. Littératures Africaines. Paris: Sílex, 1984. Impresso.

Obanya, Pai. Curriculum Reform for Educational Development in Africa: The Role of UNESCO. Dakar: Breda, 1994. Impresso.

Okpaku, Joseph. "Tradition, Culture and Criticism." Présence Africaine 70 (1969): 137-46. Impresso.

Okpewho, Isidore. African Oral Literature: Backgrounds, Character and Continuity. Bloomington, IN: Indiana UP, 1992. Impresso.

Padilha, Laura. "O ensino e a crítica das literaturas Africanas no Brasil: um caso de neocolonialidade e enfrentamento." Revista Magistro 1.1 (2010): 2-15. Impresso.

Probst, Peter. "Betwixt and Between: African Studies in Germany." The Study of Africa: Global and Transnational Engagements. Ed. Paul T. Zeleza. Dakar: CODESRIA, 2007. 157-87. Impresso.

Reis, Carlos. O conhecimento da literatura: Introdução aos estudos literários. Coimbra: Livraria Almedina, 1997. Impresso.

Rorty, Richard. Objectivisme, relativisme et vérité. Paris: Trad. Jean-Pierre Cometti. PU de France, 1994. Impresso.

Santili, Maria Aparecida. "Ano Bissexto, um tempo de saúde para a convivência em português." Actas do X Encontro de Professores Universitários Brasileiros de Literatura Portuguesa e I Colóquio Luso-Brasileiro de Professores Universitários de Literatura de Expressão Portuguesa. Lisboa/Coimbra/Porto: Instituto de Cultura Brasileira/U de Lisboa, 1984. 300-07. Impresso.

Stichweh, R. Études sur la genése du systéme scientifique moderne. Lille: PU de Lille, 1991. Impresso.

Tidjani-Serpos, Nouréini. Aspects de la critique africain: L'intellectuel négroafricaine face au roman. 2 vols. Yaoundé: Silex/Editions Nouvelles du Sud, 1996. Impresso.

Trigo, Salvato. "O ensino das Literaturas Africanas de Expressão Portuguesa em Portugal." Actas do X Encontro de Professores Universitários Brasileiros de Literatura Portuguesa e I Colóquio Luso-Brasileiro de Professores Universitários de Literatura de Expressão Portuguesa. Lisboa/Coimbra/Porto: Instituto de Cultura Brasileira/U de Lisboa, 1984. 308-324. Impresso. 
Thiong'o, Ngũgĩ wa. Homecoming: Essays on African and Caribbean Literature, Culture, and Politics. London: Heinemann, 1982. Impresso.

Werner, Michael. "Le moment philologique des sciences historiques allemandes." Qu'est-ce qu'une discipline? Ed. Jean Boutier et al. Paris: École des Hautes Études en Sciences Sociales, 2006. 171-91. Impresso.

Wiredu, Kwasi. Cultural Universals and Particulars: An African Perspective. Bloomington, IN: Indiana UP, 1996. Impresso.

Wright, Edgar. "Critical Procedures and the Evaluation of African Literature." The Critical Evaluation of African Literature. Ed. Edgar Wright. London: Heinemann, 1978. Impresso.

Zeleza, Paul T., ed. Manufacturing African Studies and Crises. Dakar: CODESRIA, 1997. Impresso.

-, ed. The Study of Africa: Global and Transnational Engagements. Dakar: CODESRIA, 2007. Impresso. 